\title{
EJNSO
}

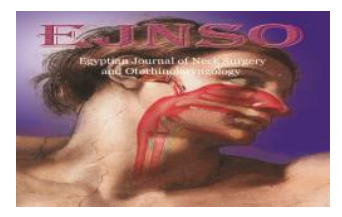

\section{Polymorphism in Cyclin D1 gene (G870A) and the risk of}

\section{squamous cell carcinoma of the larynx}

\author{
Ahmed Gaber Abd Elraheem ${ }^{1}$, Zaki F. Arf ${ }^{1}$, Ameer Effat M.Elfarash ${ }^{2}$,Nehad \\ Hassan ${ }^{1}$ \\ 1.Otorhinolaryngology Department, South Valley University Hospital, Qena, Egypt \\ 2. Genetics, faculty of Agriculture, Assiut university, Egypt.
}

\begin{abstract}
Background: Nowadays, intensive studies focus on the identification of early cancer transforming events. This may help in providing genetic markers for early cancer detection, thus predicting patient prognosis and establishing treatment strategies. Among several of the chromosomal regions and gene assemblies implicated in HNSCC tumor genesis, the arrangement of the 11q13 band particularly leading to cyclin D1gene CCND1 amplification is the most frequently genetic alteration observed. Amplification of the CCND1 gene occurs in16-38\% of HNSCC, which results in cyclin D1over expression, and it has been shown to correlate with poor prognosis, reduced disease-free interval, recurrence and lymph node metastases. A common adenine-to-guanine substitution polymorphism (A870G) in the CCND1gene at codon 242 affects splicing of the CCND1 transcript, resulting in an altered messenger RNA transcript and a longer-life protein which may cause uncontrollable cellular growth.
\end{abstract}

Aim of the work: This study was conducted to investigate the correlation between (CCND1) polymorphism and cancer larynx. Also, we studied the frequencies of CCND1 genotypes in cancer larynx patient and its relationship with the incidence of cancer, sex, age, site of lesion, tumor extension, and lymph node affection.

Patient and method: The genotyping study was done using the PCR-RFLP method in 31 patients with cancer larynx and 31 healthy controls. Cancer tissue and blood sampling was taken for DNA polymorphism from patient group, but control group were subjected only to collection of blood sample for genetic study for DNA polymorphism.

Result: Among the studied 31 patients with cancer larynx the genotype of the blood and tissue sample GG was found in 26 patients $(83.9 \%)$ while the AA genotype was found in 5 patients (16.1\%). The CCND1 genotyping in the control group was AA genotype in 2 patients $(6.5 \%)$ and was GG genotype in 29 patients $(93.5 \%)$. There were no association between the patients' genotypes and incidence of cancer larynx, sex or smoking.

Conclusion: In this work the relation of CCDN1 A870G polymorphism and the risk of cancer larynx were studied. No statistically significant difference was found between cancer and control groups as regard to genotype and allele distribution.

Key words: Cyclin D1 gene, squamous cell carcinoma, larynx

\section{$\underline{\text { Introduction }}$}

Because carcinogenesis of head and neck involves abnormalities in carcinogen metabolism, DNA repair and cell cycle control or apoptosis, polymorphism of genes involved in these pathogenic pathways are good candidates for investigation of genetic susceptibility (Scully et al., 2000).

Normal cell cycle control ensures arrest in the cell cycle allowing DNA damage in a cell to be repaired before the cell begins the process of growth, 
mitosis and division (D Amico et al., 2000).

Alteration in the CCND1 are thought to be involved in carcinogenesis because activation of CCND1 and overexpression have been found in a variety of tumors, including those of the breast, head and neck, esophagus and lung (Toyoda et al., 2000).

The activity of CCND1 reaches a maximum during G1 phase; and is associated with CDK4 and CDK6 in mid to late G1 phase, therefore, it is one of the major cyclins involved in this transition (Sherr 1996).

Of the polymorphisms identified, the cyclin Dl G/A870 polymorphism has received the most investigation. This polymorphism does not lead to an amino acid change, but the variant nucleotide interferes with splicing froe exon 4 to exon 5 because of its unique localization within a conserved splice donor region. It has been postulated that A allele enhances alternative gene splicing, leading to altered protein that does not contain the sequences involved in protein turnover.

Therefore, it has been suggested that DNA damage in cells from subjects with the A allele may bypass the G1/S check point of the cell cycle control mechanism more easily than damage in cells that not carrying polymorphism (Kong et al., 2000).

Because CCND1 plays a critical role in cell cycle control and there is evidence that reduced DNA repair capacity is associated with increased risk of HNSCC (Cheng et al., 1998).

The polymorphism frequency in the Caucasian population is approximately $44 \% \mathrm{~A}$ and $56 \% \mathrm{G}$, depending on the study population, but large variances between racial and ethnic groups have been reported. Owing to the significance of cyclin Dl in human cancer, a large number of epidemiological studies have been challenged the influence of this particular polymorphism in cancer susceptibility and disease outcome (Sanyal et al., 2004). Some studies link the A allele to increases cancer risk or earlier age of cancer onset and the other implicated the $G$ allele with increased cancer risk.

These results indicate that individual alleles harbor differential effects in distinct tumor types. However, within a specific tumor type there have been disparate results regarding the significance of the polymorphism. These disparities could be reflective of the study population and the possible involvement of external factors e.g. smoking or obesity that have been suggested to cooperate with the polymorphism in specific studies. The issues whether the G/A870 polymorphism is the specific causal variant and whether there are other polymorphisms at this locus that are biologically relevant remain to be resolved (Shu et al., 2005).

\section{Patients and Methods:}

During the period from March 2014 to June 2015 a sixty-two patients were enrolled in this study. 46 were males and 16 were females. They were divided into two groups: group $\mathrm{A}$; cancer larynx and group B control group (clinically normal larynx). The age of group A ranged from 34 to 80 years old with the mean age $58.58 \pm$ 12.30 while the age of group B ranged from 13to72 years old with the mean age $34.45 \pm 13.24$. This study was done in ENT department faculty of medicine South Valley University and the Genetics Department, Faculty of Agriculture, Assiut University. The group A was subjected to full general and ENT examination. Routine laboratory investigation for everyone were done and CT scan of the neck were done for all patients in groups $\mathrm{A}$ for detection of site, size, extension of 
the tumor and lymph node affection. Under general anesthesia and endotracheal intubation (intravenous anesthesia by propofol $1.5 \mathrm{mg} / \mathrm{kg}$, short acting muscle relaxant succinylcholine chloride $1.5 \mathrm{mg} / \mathrm{kg}$ with maintenance inhalation anesthesia and mechanical ventilator. Direct laryngoscope was done for evaluation of the size, site, extension, taking biopsy for histopathology and tissue sampling for DNA polymorphism. Also, blood sampling was taken for DNA polymorphism from group A but group B were subjected only to collection of blood sample for genetic study for DNA polymorphism. The characteristic of cancer larynx patient is shown in table (1)

Table (1) Characteristic of cancer larynx patient

\begin{tabular}{|l|c|}
\hline Characteristic & Number of patient (\%) \\
\hline Age & $34-80$ \\
Range & $58.68 \pm 12.30$ \\
Mean \pm SD & $31(100 \%)$ \\
Sex & $27(87 \%)$ \\
Male & $4(13 \%)$ \\
Female & $11(35.5 \%)$ \\
Site of lesion & $12(38.7)$ \\
Glottic & $8(25.8)$ \\
Supraglottic & $11(35.5 \%)$ \\
Transglottic & $10(32.3 \%)$ \\
Tumor extension & $1(3.2 \%)$ \\
T1 & $9(29.0 \%)$ \\
T2 & \\
T3 & \\
T4 & $15(48.4 \%)$ \\
Histological & $7(22.6 \%)$ \\
differentiation & $9(29.0 \%)$ \\
G1 & \\
G2 & $11(35.5 \%)$ \\
G3 & $20(64.5 \%)$ \\
Lymph node & \\
N- & \\
N+ & \\
\hline
\end{tabular}

\section{Samples}

Blood samples and cancer tissue sample from cancer larynx patient group A were taken and blood samples were taken from control group B Blood samples were collected in EDTAcontaining tubes.

\section{DNA extraction:}

Total genomic DNA was isolated using PureLink ${ }^{\circledR}$ Genomic DNA Kits for purification of genomic DNA. The kit was used according to the manufacturer's instructions as following:

\section{A. Preparing Lysates}

a- Set a water bath or heat block at $55^{\circ} \mathrm{C}$.

b- Place 2-5 punches of dried blood spot $(2-3 \mathrm{~mm}$ in size) in a sterile micro centrifuge tube.

c- Add $180 \mu \mathrm{L} \quad$ PureLink ${ }^{\circledR}$ Genomic Digestion Buffer and 20 $\mu \mathrm{L}$ Proteinase K (supplied with the kit) to the tube. Mix well by vortexing. Ensure the pieces are completely immersed in buffer.

d- Incubate at $55^{\circ} \mathrm{C}$ with occasional vortexing for 30 minutes.

e-Centrifuge the sample at maximum speed for 2-3 minutes at room temperature to pellet paper fibers. Transfer the sample to a clean, sterile micro centrifuge tube.

f- Add $20 \mu \mathrm{L}$ RNase A (supplied in the kit) to the lysate, mix well by brief vortexing, and incubate at room temperature for 2 minutes.

g-Add $\quad 200 \mu \mathrm{L} \quad$ PureLink ${ }^{\circledR}$ Genomic Lysis/Binding Buffer and mix well by vortexing to obtain a homogenous solution.

h- Add $200 \mu \mathrm{L}$ 96-100\% ethanol to the lysate Mix well by vortexing for 5 seconds to yield a homogenous solution.

Note: When processing multiple samples, you may prepare a master Buffer/ ethanol Mix by mixing $200 \mu \mathrm{L}$ Lysis/Binding Buffer and $200 \mu \mathrm{L}$ 96-100\% ethanol for each sample. 


\section{B. Binding DNA}

a-Remove a PureLink ${ }^{\circledR}$ Spin Column in a Collection Tube from the package.

b-Add the lysate $(\sim 640 \quad \mu \mathrm{L})$ prepared with PureLink ${ }^{\circledR}$ Genomic Lysis/Binding Buffer and ethanol to the PureLink ${ }^{\circledR}$ Spin Column.

c- Centrifuge the column at 10,000 $\times \mathrm{g}$ for 1 minute at room temperature.

Note: If a processing $>200 \mu \mathrm{L}$ starting material such as blood, buccal swabs, or Oragene ${ }^{\mathrm{TM}}$ preserved saliva, we perform multiple loading of the lysate by transferring any remaining lysate to the same PureLink® Spin Column (above) and centrifuge at $10,000 \times \mathrm{g}$ for one minute.

$\mathrm{d}$ - Discard the collection tube and place the spin column into a clean PureLink ${ }^{\circledR} \quad$ Collection Tube supplied with the kit.

\section{Washing DNA}

a- Add $500 \mu \mathrm{L}$ Wash Buffer one prepared with ethanol to the column.

b-Centrifuge column at room temperature at $10,000 \times \mathrm{g}$ for one minute.

c- Discard the collection tube and place the spin column into a clean PureLink ${ }^{\circledR}$ collection tube supplied with the kit.

d-Add $500 \mu \mathrm{L}$ wash Buffer 2 prepared with ethanol to the column.

e-Centrifuge the column at maximum speed for 3 minutes at room temperature. Discard collection tube.

\section{Eluting DNA.}

a- Place the spin column in a sterile $1.5-\mathrm{mL}$ microcentrifuge tube. b- Add 25-200 $\mu \mathrm{L}$ of PureLink ${ }^{\circledR}$ Genomic Elution Buffer to the column. See Elution Parameters to choose the suitable elution volume for your needs.

c- Incubate at room temperature for one minute. Centrifuge the column at maximum speed for one minute at room temperature. The tube contains purified genomic DNA.

d- Remove and discard the column. Store the purified DNA at $-20^{\circ} \mathrm{C}$ or use DNA for the desired downstream application.

\section{Preparation of $\mathrm{PCR}$ reactions:}

In order to identify samples with the G870A polymorphism in the Cyclin D1 gene of squamous cell carcinoma of the larynx, a 167-bp fragments containing polymorphic nucleotide was amplified by PCR using specific primers: 5'GTGAAGTTCATTTCCAATCCG-3' in exon 4 and

\section{5'GGGACATCACCCTCACTTAC-} 3 ' in intron 4 (Cortessis et al., 2003).

To perform several parallel reactions, a master mix containing water, buffer, dNTPs, $\mathrm{MgCl} 2$, and TaqDNA Polymerase was prepared in a single tube. Primers and template DNA solutions were then added. The master mix was prepared in a $1.5 \mathrm{ml}$ Eppendorf tube, according to the number of PCR reactions to be performed, with an extra reaction included for compensating the loss of solution due to frequent pipetting. An aliquot of $22.5 \mu 1$ master mix solution was dispensed in each PCR tube $(0.5$ $\mathrm{ml}$ ), containing $2.5 \mu \mathrm{l}$ of the appropriate template DNA dilution as described in table (2). 
Table (2). Components of each PCR reaction

\begin{tabular}{|l|c|}
\hline \multicolumn{1}{|c|}{ Component } & $\begin{array}{c}\text { Amount of one PCR } \\
\text { reaction }\end{array}$ \\
\hline $\mathrm{dH}_{2} \mathrm{O}$ & $9.5 \mu 1$ \\
\hline 10 Xreaction buffer & $3.0 \mu \mathrm{l}$ \\
\hline dNTP's mix & $3.0 \mu 1$ \\
\hline Forward Primer & $1.25 \mu \mathrm{l}$ \\
\hline Reverse Primer & $1.25 \mu 1$ \\
\hline Taq polymerase & $0.5 \mu 1$ \\
\hline $\mathrm{MgCl} 2$ & $4.0 \mu \mathrm{l}$ \\
\hline Template DNA & $2.5 \mu \mathrm{l}$ \\
\hline Total volume & $\mathbf{2 5 . 0} \boldsymbol{\mu l}$ \\
\hline
\end{tabular}

a- PCR program and temperature profile for DNA amplification, a TECHNE thermocycler (Model FTGEN5D, TECHNE, Cambridge Ltd, Duxford, and Cambridge, U.K.) was used. The thermocycler program was as follows: initial denaturation for 3 minutes at $94^{\circ} \mathrm{C}$ (first step), 30 cycles of 1 minute at 92, 1 minutes at $60^{\circ} \mathrm{C}$ and 1 minutes at $72^{\circ} \mathrm{C}$ (second step), 10 minutes at $72^{\circ} \mathrm{C}$ (third step), then followed by a final hold at $4^{\circ} \mathrm{C}$.

b- PCR Purification: The QIA quick PCR Purification kit (Qiagen) was used to purify DNA fragments from primers, polymerases, unincorporated nucleotides, and salts using QIA quick spin columns in a micro centrifuge. The QIA quick system used a bind-wash-elute procedure. DNA was adsorbed to the silica-membrane in the presence of high salt while contaminants passing through the column. Impurities were efficiently washed away, and the pure DNA was eluted with this buffer. Firstly, $45 \mu \mathrm{l}$ of PCR product and $250 \mu \mathrm{l}$ Buffer PB were added to a QIA quick spin column for DNA binding and then centrifuged at 11,000 rpm for one min. The flow-through was discarded. Secondly, $750 \mu 1$ Buffer $P E$ was added to the QIA quick spin column for washing and then centrifuged at 11,000 rpm for one min. The flow-through was discarded. The column was centrifuged at $14,000 \mathrm{rpm}$ for $2 \mathrm{~min}$ and then the column was placed in a clean $1.5 \mathrm{ml}$ micro centrifuge tube. Finally, $50 \mu 1$ Buffer EB (10 mMTris-Cl, pH 8.5) was added to the center of QIA 9 quick membrane for eluting and then centrifuged at $11,000 \mathrm{rpm}$ for one min. The purified DNA was ready for use in subsequent applications.

c- Restriction digests of the PCR Product: A Scr FI (Fermentas) restriction endonuclease enzyme was used to cut the Purified PCR products to differentiate between the samples in the polymorphic site. Samples with $\mathrm{G}$ in the polymorphic site shall be digested into two fragments, $145 \mathrm{bp}$ and $22 \mathrm{bp}$, while those with A shall not because of the absence of a Scr FI restriction site (Cortessis et al.,2003). The Digestion was performed in $20 \mu \mathrm{l}$ in accordance to the Fermentas protocols as following:

- DNA $\quad 10 \mu 1$

- Scr FI $0.5 \mu 1$

- 10x buffer $2 \mu 1$

- $\mathrm{H} 2 \mathrm{o} \quad 7.5 \mu \mathrm{l}$

The digests were mixed via centrifugation $(13,000 \mathrm{rpm}$ for 5 seconds). The reaction was performed in microfuge tubes overnight at $37^{\circ} \mathrm{C}$. When digestion was completed $4 \mu 16$ $x$ Gel loading buffer was added to the reaction and the digested DNA was viewed on $8 \%$ polyacrylamide gel.

d-Polyacrylamide

Electrophoresis

The obtained Purified PCR products of each reaction and a HyperLadder ${ }^{\mathrm{TM}}$ 50bp (Bioline) were electrophoresed onto a $8 \%$ polyacrylamide solution (10 
$\mathrm{ml}$ of $40 \%$ acrylamide, $5 \mathrm{ml} 10 \times \mathrm{TBE}$ buffer, $34.7 \mathrm{ml} \mathrm{H} 2 \mathrm{O}, 234 \mu \mathrm{l} 10 \%$ APS, $100 \mu 1$ TEMED) was poured into a mold which was fitted with a wellforming comb and polymerized completely at room temperature (about 1 hour) Figure (1).

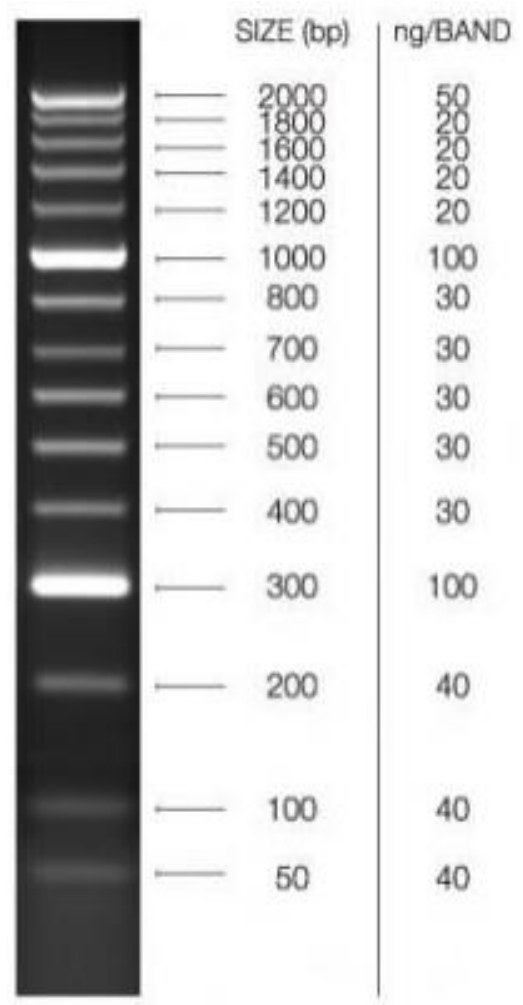

Figure (1): Bands of the Hyper Ladder ${ }^{\mathrm{TM}}$ 50bp (Bioline) performing different molecular weights.

The gel was mounted in the electrophoresis apparatus. The reservoir of the electrophoresis tank was filled with $1 \mathrm{x}$ TBE electrophoresis buffer ( 89 mMTris, 89 $\mathrm{mM}$ boric acid and $2 \mathrm{mM}$ EDTA). The digested PCR products were mixed with loading buffer and loaded to the bottom of the sample wells with a micropipette.

Electrophoresis was performed for about $60 \mathrm{~min}$ to $120 \mathrm{~min}$ at $150 \mathrm{~V}$ at room temperature until the tracking dye reached the bottom of the gel layer. The gel apparatus was disassembled and the glass sandwich containing the gel was removed. The gel was transferred into an appropriate container with ethidium bromide staining solution for $15 \mathrm{~min}$ and rocked gently to make the staining solution over the gel. After that, the gel was placed on an ultraviolet light box and pictures of the DNA separation pattern stained by fluorescent ethidium bromide were recorded with a video camera (Fig 2, 3).

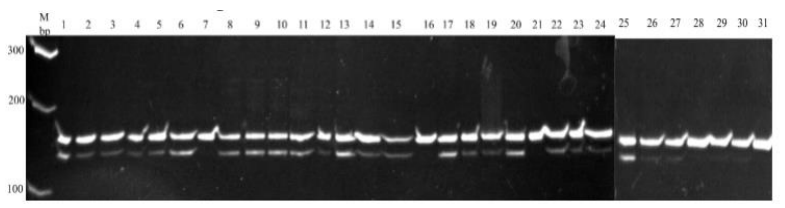

Figure (2): DNA separation pattern of the patients

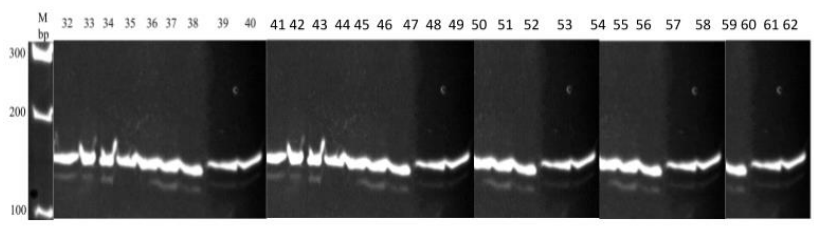

Figure (3): DNA separation pattern of the control

\section{Statistical analysis:}

Date entry and data analysis were done using SPSS version 19 (Statistical Package for Social Science). Data were presented as mean and standard error. Chi-square and Fisher Exact tests were used to compare between qualitative variables. Mann-Whitney test was used to compare between two quantitative variables in case of non-parametric data. P-value considered statistically significant when $\mathrm{P}<0.05$.

\section{Results:}

Thirty-one patients with cancer larynx with 31 healthy control were included in this study. Genotype 
frequencies of patients and control are detailed in table 3 .

Table (3) The CCND1 genotype distribution in larynx cancer patient and control group.

\begin{tabular}{|l|c|c|c|c|l|}
\hline $\begin{array}{l}\text { Result of } \\
\text { CCND1 } \\
\text { genotype }\end{array}$ & \multicolumn{2}{|l|}{$\begin{array}{l}\text { Patient } \\
\mathrm{N}=31\end{array}$} & \multicolumn{2}{|c|}{$\begin{array}{l}\text { Control } \\
\mathrm{N}=31\end{array}$} & \multirow{2}{*}{.value } \\
\cline { 2 - 5 } & $\mathrm{N}$ & $\%$ & $\mathrm{~N}$ & $\%$ & \\
\hline AA & 5 & 16.1 & 2 & 6.5 & 0.422 \\
\hline GG & 26 & 83.9 & 29 & 93.5 & \\
\hline
\end{tabular}

No statistically significant difference was found between the studied control group regarding genotype distribution.

Clincopathological features of patients according to CCDN1 genotypes are present in table 4. With no statistically significant association between CCDN1 and smoking state, tumor stage, lymph node affection, tumor differentiation and tumor site in cancer larynx patient. Glottic tumor were more frequently seen in patient with GG genotype. Also, there was a slight relation between the homozygote GG genotype and the lymph node affection, well differentiation and early tumor stage $(\mathrm{T})$ but all are statistically non-significant.

Table (4) Correlation of CCND1 genotype with clinical feature of cancer larynx patients

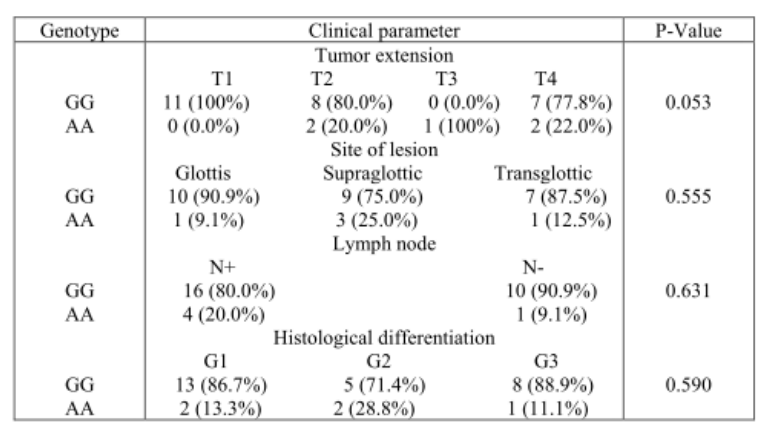
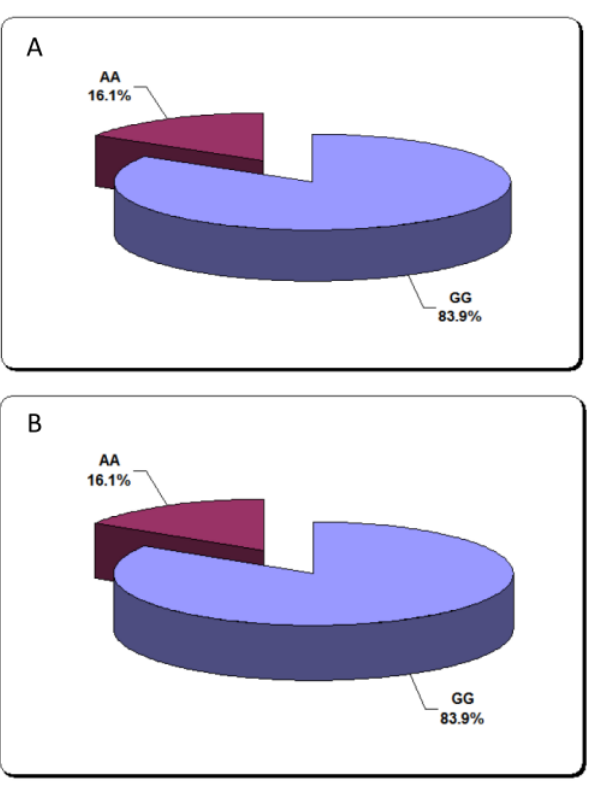

Figure (4): The frequency distribution of CCND1 genotypes among laryngeal cancer patient in both blood (A) and tissue (B).

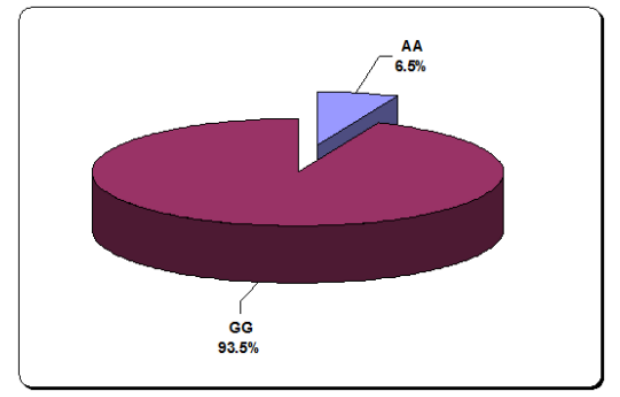

Figure (5): Results of CCND1 in blood in control group

\section{Discussion:}

Laryngeal cancer is a multifactorial disease, such as other cancer types and is induced by both genetic and environmental factors. Even though laryngeal cancer is not one of the most common seen cancers world-wide, its incidence is reported to be $8 \%$ of all tumors. It constitutes about $30 \%$ of all malignant tumors in the head and neck area (Boffettaet al., 2001).

Tobacco smoking and consumption of alcoholic beverages are a wellknown risk factors for cancer larynx (Tuncer et al., 2009). 
Since the mortality of cancer is mostly due to late detection of the disease as in supraglottic region, more specific markers are needed for early diagnosis. In this respect, common molecular alterations considered to be a potential marker of the laryngeal tumors which have taken a great concern with cancer researches. As one of these candidate markers; rearrangement of 11q13 region, which particularly leads to amplification of CyclinD1 (CCND1), is commonly observed in laryngeal cancers (Rydzanicz et al., 2006).

CyclinD1 is a key gene in the cell cycle regulation which controls the G1-S transition during the cell cycle. High activity of CCND1 causes premature cell passage through G1 check-point which results in accumulation of damaged DNA and finally results in abnormal cell proliferation (Pabalan et al., 2008).

CyclinDlgene is one of these important regulators of the cell cycle and known to be over expressed in numerous cancer types. This observed the importance of CCND1 up regulation in carcinogenesis is due to its critical function on G1-S transition during the cell cycle (Knudsen et al., 2006).

Cyclin D1 is a product of CCND1 and forms a complex with Cyclin dependent kinases (CDKs) Cdk4 and Cdk6which control the G1-S transition.

Furthermore, CyclinD1 catalyzes the phosphorylation of retinoblastoma $(\mathrm{Rb})$ protein which means that the disassociation of transcription factor $\mathrm{E} 2 \mathrm{~F}$ from $\mathrm{Rb}$ and eventually the transcription of "cell division" genes (Nishimoto et al., 2004).

In addition to the known amplification mechanism, a specific variant of CCND1 generates an alternative transcript with a prolonged half-life, which eventually means an increased number of active CCND1.
This specific variant creates a guanine adenine transition at codon 242 on exon 4 which inhibits an amino acid substitution (pro241pro) yet production of a truncated splice variant, called transcript $b$, without PEST motif containing exon 5 (Betticher et al., 1995).

Since PEST domain is critical for the degradation of CCND1, transcript $b$ (870A allele) has been shown to have a longer half-life than its wild form transcript a (G870).Thus, individuals with CCND1870A genotype are suggested to more easily bypass the G1-S check point and contribute to cancer development (Zhang et al., 2011).

Although the effects of CCND1 polymorphism have been tested in various cancer types, there are only a limited number of studies that subjected directly to laryngeal squamous cell cancer since this disease is mostly investigated within the head and neck cancer group. Studies that have been presented so far indicate contradictory results (Matthias et al., 1998).

In our study the mean age of patient was $58.58 \pm 12.30$ ranging from (34.0 - 80.0) year old. So, this study going with the Results Recorded by Hazem et al., 2014 in their study and with Aysegul et al., 2013 study where the mean age was 61.59 in 65 patients all were male. Also, we agree with Parkin et al., 2005 who reported that laryngeal cancer is generally a disease of the elderly, with a peak incidence in the 50 s and $60 \mathrm{~s}$.

In our study 27 patients were males, whereas 4 patients were females; the male to female ratio was 9:1. This relatively lower than ratio reported by Hazem et al., 2014 which was 15 males: 1 female but both are much higher than the study of Snyder et al., 2006 who reported that carcinomas of the larynx are four times more frequent 
in men than in women in the USA. Also, Jemal et al., 2008 reported that the male to female ratios in terms of incidence rates are greater than 5: 1 .

In our study we found that 23 patients out of $31(74.2 \%)$ were smokers, where as $25.8 \%$ (8 cases) were nonsmokers which is Relatively low than result recorded by Hazem et al., 2014 where as $86.1 \%$ were smokers and those recorded by Aysegul et al., 2013 were (96.9\%) and those by Licitra et al., 2003 who reported that smoking is responsible for up to $95 \%$ of causes of laryngeal cancer.

Our study showed that 12 patients $(38.7 \%)$ were affected in supraglottic area followed by Glottic and Transglottic area 11 and 8 patients (35.5\% and $25.8 \%$ ) respectively with no affection in subglottic area and this not coincidence with that reported in Hazem et al., 2014 study, where the distribution was as follow $62.4 \%$ were affected in the glottic - supraglottic regions, followed by Transglottic region in $20.7 \%$. The glottic region was affected only in $10.8 \%, 5.1 \%$ had only supraglottic and only $1 \%$ of patient had subglottic tumor which make it rare subsite for laryngeal carcinoma. Also, we disagree with Luna-Ortiz et.al. who carried out a study on 48 patients with laryngeal cancer and the results according to location were as follows: supraglottic region in $14(29.1 \%)$ patients, glottic in $30(62.5 \%)$ patients, and only subglottic region in one patient (2.08\%).

In this study $\mathrm{T}$ classification was found to be 11 patients T1 (35.5\%), 10 patients with T2 (32.3\%), and 9 patients T4 $(29.1 \%)$ with only one patient T3 $(3.2 \%)$. So we disagree with study of Hazem et al., 2014 Aysegul et al., 2013 and Rydzanicz et al., 2006 regarding
$\mathrm{T}$ classification that $\mathrm{T} 1(12.1 \%), \mathrm{T} 2$ $(12.8 \%), \mathrm{T} 3(66.1 \%), \mathrm{T} 4(8.7 \%)$ in Hazem et al., (2016) While Aysegul et al., 2013 showed that 7 patient T1, 11 patient $\mathrm{T} 2,37$ patient $\mathrm{T} 3$, and 9 patient T4. Those of Rydzanicz 2006 were T1(1.5\%), T2 (10.6\%), T3 (57.6 $\%) \& \mathrm{~T} 4(30.3 \%)$.

In our study15 patients (48.4\%) were grade 1, 7 patients $(22.6 \%)$ were grade 2 and 9 patients were grade 3 $(29 \%)$. This differ from those of Rydzanicz et al., 2006 who Reported that 26 patients (39\%) were grade 1, 34 patients $(51.5 \%)$ were grade 2 and 6 patients $(9.1 \%)$ were grade 3 out of 66 patients and from those of Aysegul et al., 2013 who reported that 9 patients $(13.8 \%)$ were grade 3 , 44 patients $(67.7 \%)$ were grade $2 \&$ $11(16.9 \%)$ patients were grade1 out of 65 patients. In our study the clinical and radiological affection of lymph node were $20(64.5 \%)$ of patients where as in $11(35.5 \%)$ of patients were no lymph node affection. So, we agree with Aysegul et al., 2013 in their study, which showed that 38 patients (58.4\%) without lymph node affection and 27 patients (42.6\%) with lymph node affection and with Hazem, M et.al. 2014 in their study which showed that 179 patients $(61.9 \%)$ without lymph node affection and 110 patients (38\%) with lymph node affection and with Rydzanicz et al., 2006 who reported that lymph node affection in their study was negative in 38 patients $(57.9 \%)$ and positive in 28 patients (42.4\%).

Thirty-one patients with cancer larynx and 31 healthy controls were included in the study. Genotype and allele frequencies of patients and controls are studied and there was no statistically significant difference was found between study and control groups as regard genotypes and allele distribution where 26 patients $(83.9 \%)$ were GG genotype and 5 patients 
(16.1\%) were AA genotype while the control group was 29 cases $(93.5 \%)$ were GG genotype and 2 patients (6.5\%) were AA genotype.

The heterozygous GA genotype was $(0 \%)$ in both control and cancer larynx patient.

In our study the frequencies of CCND1 genotypes in cancer larynx patient was studied with its relationship with the incidence of cancer, sex, age, site of lesion, tumor extension, lymph node affection and smoking. There was no association between the patient genotype and incidence of cancer larynx, sex or smoking.

However there is a slight increase in lymph node affection with GG genotype as out of 20 patients $(64.5 \%)$ with positive lymph node, $16(80 \%)$ patients were GG genotype and 4 patients (20\%) were AA genotype.

Also, the homozygote GG genotype show increase in incidence with well differentiated tumor distributed as follow 13,5,8 patient with grade1, grade2,grade 3 and with $\mathrm{T} 1$ tumor extension represented as 11,8,0,7 patients, with $\mathrm{T} 1, \mathrm{~T} 2, \mathrm{~T} 3, \mathrm{~T} 4$ and also with glottic carcinoma as10, 9,7 of patients with glottic, supraglottic, transglottic respectively however all was non statistically significant and this is going with the result of Aysegal et al., 2013 who reported that no significant association was detected between CCND1 genotypes and laryngeal squamous cell carcinoma development, tumor $\mathrm{T}$ stages, localization, histological tumor differentiation, presence of reflux. Except for that he detected a significant association between CCND1 G allele and presence of perineural invasion. Also, we agree with Monteiro et al. 2004 regarding as no significant association was observed between CCND1 A870G genotypes and disease stage, tumor differentiation grade in their study.

We disagree with Matthias et al., (1998) in their study which reported that the Cyclin D1 GG870 genotype has been found to be associated with poorly differentiated tumors.

Also we disagree with

Papadimitrakopoulou et al., (2009) who reported in their study that individuals with A allele (both AA and AG) have higher cancer progression rate when compared to subjects with GG genotype and CCND1genotype and protein expression was suggested to be important risk markers for laryngeal cancer, Nishimoto et al., (2004) suggested that CCND1 AA genotype is a risk factor, especially between nonalcoholic, for squamous cell carcinoma of the larynx , and also we agree with Rydzanicz et al., (2006) in their study as they reported that the wild type GG genotype was suggested to be the "protective variant" for cancer larynx and AA genotype was suggested to be a risk factor for head and neck squamous cell cancer.

\section{Conclusion:}

A sixty tow patients were enrolled in this study. 46 were males and 16 were females. They were divided into two groups: group A; cancer larynx and group B control group (clinically normal larynx).

In this work the relation of CCND1 G870A polymorphism and the risk of cancer larynx were studied. No statistically significant difference was found between cancer and control groups as regard to genotype and allele distribution

There was no significant difference in cancer larynx patients as regard CCND1genotypes and alleles A and G. These results indicate that in our population (especially upper Egypt patient) this gene variant carry no risk 
in incidence of cancer larynx but the possible involvement of external environmental factor (e.g. smoking).

\section{Recommendation:}

1. Further evaluation of cyclin D1 gene in larger group of patients and control group should include smoker and non-smoker individual.

2. Evaluation of other molecular marker of cancer larynx due to the great importance of these markers in the early diagnosis and management and so in better patient outcome

\section{Conflict of interest}

The authors declare no competing interests.

\section{Reference:}

1. Amico D M, Hulit J, Amanatullah ,DF, Zafonate BT, AlbaneseC, Bou-zahzah B, FuM, Augenlicht LH, Donehower LA, Takemaru KI, Moon RT, Davis R, Lisanti MP, Shtutman, M, Zhurinsky J, Benzeev A, Troussard AA, Dedhar S, and Pestell RG, (2000): The inter grin linked kinas regulates the cyclin D1 gene through glycogen synthase kinase 3 beta and $\mathrm{C}$ AMP responsive element binding protein dependent pathway. J. Biol. Chem., 275, 32649-32657.

2. Aysegul Verim, Nazli Ozkan, Saime Turan, Gurbet Korkmaz, Canan Cacina, IlhanYaylım and TurgayIsbir ,(2013): Association of the Cylin D1 G870A Polymorphism with Laryngeal Cancer: Are they Really Related? Asian Pac J Cancer Prev, 14 (12), 7629-7634

3. Boffetta P, Ye W, Adami HO, Mucci LA and Nyrén O, (2001): Risk of cancers of the lung, head and neck in patients hospitalized for alcoholism in .Sweden. Br J Cancer, 85, 678-82

4.Betticher DC, Thatcher N,Altermatt HJ, (1995) : Alternate splicing produces a novel cyclin D1 transcript. Oncogene, 11,100511

5.Cheng, L, Eicher SA, Gua Z, Hong WK, Spit Z MR, and Wei Q (1998): Reduced DNA repair capcity in head and neck cancer patient. Cancer epidermiol biomarker prev., 7,465-468

6.Cortessis VK, Siegmund K, Xue S, Ross RK, Yu MC (2003): A case-control study of cyclin D1 CCND1 870A $\rightarrow$ G polymorphism and bladder cancer. Carcinogenesis. 2003; 24:16451650

7.Deng L, Zhao XR, Pan KF, Wang $\mathrm{Y}$, Deng XY, Lu YY and Cao Y,(2002): $\quad$ Cyclin D1 polymorphism and the susceptibility to NPC using DHPLC, Sheng wuhuaxueyu sheng wuwu li xue bao Actabiochimica et biophysica Sinica 34 (2002):16-20

8. Hazem M. Abdel Tawab, Mikhail W. AbdElMessih, Nasser AA. AlNaggar and Louay $S$ El Sharkawy, (2014): Study of the epidemiology and management of laryngeal cancer in Kasr Al-Aini Hospital. The Egyptian Journal of Otolaryngology2014, 30:208-214

9. Jemal A, Siegel R, Ward E, Hao $\mathrm{Y}, \mathrm{Xu} \mathrm{J}$, Murray $\mathrm{T}$ and Thun MJ, (2008): Cancer statistics CA. Cancer J Clin; 58:71-96.

10. Knudsen KE, Diehl JA, Haiman CA and Knudsen ES, (2006): Cyclin D1polymorphism, aberrant splicing and cancer risk. Oncogene, 25, 1620-8.

11. Kong S, Amos CI, Luthra R, Lynch PM, Levin B, and 
Frazier ML, (2000): Effect of cyclin D1 polymorphism on age onset of hereditary non polyposis colorectal cancer cancer Res,60,249-252

12. Licitra L, Bernier J, Grandi C, Locati L, Merlano M, Gatta G and LefebvreJL, (2003): Cancer of the larynx: Oncology /Hematology 2003; 47:65-80.

13. Luna-Ortiz $\mathrm{K}$, VillavicencioValencia V, Pasche P and A Lavin-Lozano, (2010): Laryngeal cancer in patients younger versus older than 40years old: a matched-paired analysis. ActaOtorrinolaringolEsp 2010; 62:113-118.

14. Matthias C, Branigan K, Jahnke V , Leder K , Haas J, Heighway J, Jones PW, Strange RC, Fryer AA and Hoban PR , (1998) Polymorphism within the cyclin Dl gene is associated with prognosis in patients with squamous cell carcinoma of the head and neck, Clin Cancer Res 4 2411-2418.

15. Monteiro E, Varzim G, Pires AM, Teixeira $\mathrm{M}$ and Lopes $\mathrm{C}$, (2004): Cyclin D1 A870G polymorphism and amplification in laryngeal squamous cell carcinoma: implications of tumor localization and tobacco exposure Cancer Detect Prev, 28, 237-43.

16. Nishimoto IN, Pinheiro NA and Rogatto SR, (2004): Cyclin D1 gene polymorphism as a risk factor for squamous cell carcinoma of the upper aerodigestive system in nonalcoholics. Oral Oncol 40, 604-10

17. Pabalan N, Bapat B, Sung L, Jarjanazi H, Francisco-Pabalan $\mathrm{O}$ and Ozcelik H, (2008): Cyclin D1 Pro241Pro
(CCND1-G870A)

polymorphism is associated with increased cancer risk in human populations: a metaanalysis. Cancer. Epidemiol Biomarkers Prev, 17, 2773-81

18. Papadimitrakopoulou V, Izzo JG, Liu DD, Myers J, Ceron TL, Lewin J, William WN, Atwell A, Lee J, Gillenwater A, El-Naggar A, Wu $\mathrm{X}$, Lippman SM, Hittelman WN and Hong WK, (2009): CyclinD1 and cancer development in laryngeal premalignancy patients. Cancer Prev Res, 2, 14-21.

19. Parkin DM, Bray F, Ferlay J and Pisani P, (2005): Global cancer statistics CA. Cancer J Clin 2005; 55:74-108.

20. Rydzanicz M, Golusinski P, Mielcarek-Kuchta D, Golusinski $W$ and Szyfter K, (2006) : Cyclin Dl gene (CCND1) polymorphism and the risk of squamous cell carcinoma of the larynx, Eur Arch Oto rhinolaryngol 263 (2006) 43-48.

21. Sanyal S., Festa F, Sakano S, Zhang Z, Steineck G, Norming U, Wijkstrom H., Larsson P, Kumar $\mathrm{R}$ and Hemminki $\mathrm{K}$, (2004):Polymorphisms in DNA repair and metabolic genes in bladder cancer, Carcinogenesis 25 (2004) 729734.

22. Scully C, Field JK and Tanzawa H, (2000): Genetic aberrations in oral or head and neck squamous cell carcinoma (SCCHN): 1. Carcinogen metabolism, DNA repair and cell cycle control. Oral Oncol 36:256-263

23. Sherr CJ, (1996): cancer cell cycle Science,274, 1672-1677 
Shu X.O, Moore D.B , Cai Q, Cheng J, Wen W, Pierce L, Cai $\mathrm{H}$, Gao YT and Zheng W, (2005): Association of cyclin Dl genotype with breast cancer risk and survival, Cancer Epidemiol Biomarkers Prev 14 (2005) 91-97.

24. Snyder M, William ML and Daniel DL, (2007): Glottic cancer: follow-up: Department of Otorhinolaryngology. Head and Neck Surgery, University of Nebraska Medical Center 2006. Available at: topic 688htm.

25. Toyoda, H., Nakamura T., Shinoda M.,Suzuk.,T.,Hatooka, S., Kobayashi, S., Ohashi, K., SetoM., Shiku H., and Nakamura S, (2000): Cyclin D1 expression is useful as prognostic indicator for advanced esophageal carcinoma, but not for superficial tumors.

26. Tuncer M, Ozgul N, Olcayto EO, Gultekin M and Erdin B, (2009): Turkish Republic, Ministry of Health, National Cancer Control Department, National Cancer Programme, 2009-15.

27. Zhang P (1999): The cell cycle and development: redundant roles of cell cycle regulators, Current opinion in cell biology 11 (1999) 655-662.

28. Zheng Y, Shen H, Sturgis EM, Wang LE, Eicher SA, Strom SS,Frazier ML, Spitz MR and Wei Q, (2001): Cyclin D1 polymorphism and risk for squamous cell carcinoma of the head and neck : a casecontrol study. Carcinogenesis 22:1195-1199. 